\title{
Using Poll App to Improve Active Learning in an Engineering Project Man- agement Course Offered to Civil and Environmental Engineering Students
}

\section{Dr. Long Duy Nguyen P.E., Florida Gulf Coast University}

Dr. Long Nguyen is an Associate Professor in the Department of Environmental and Civil Engineering at Florida Gulf Coast University (FGCU). Before joining FGCU, he was the deputy director of Tuan Le Construction and a lecturer at Ho Chi Minh City University of Technology (HCMUT). Prior to his tenure at HCMUT, he worked as a construction consultant at Jax Kneppers Associates, Inc. in Walnut Creek, CA. He is a professional engineer registered in California. He earned his B.Eng. in Civil Engineering from HCMUT in 1999, M.Eng. in Construction Engineering and Management from Asian Institute of Technology (AIT) in 2003, and M.S. and Ph.D. in Engineering - Civil and Environmental Engineering from the University of California, Berkeley in 2005 and 2007, respectively.

\section{Dr. Robert O’Neill P.E., Florida Gulf Coast University}

Dr. ROBERT (BOB) J. O'NEILL is Professor and Chair of the Department of Environmental and Civil Engineering, U.A. Whitaker College of Engineering, Florida Gulf Coast University. He received a B.S. from the United States Military Academy in 1975, an M.S. in Structural Engineering and an M.S. in Geotechnical Engineering from Stanford University in 1984 and a Ph.D. in Structural Engineering from Kansas State University in 1993. Prior to his coming to FGCU he was a Professor of Engineering at Roger Williams University and an Associate Professor and Director of the Civil Engineering Analysis Group at the United States Military Academy. Dr. O' Neill is a retired Lieutenant Colonel, U.S. Army Corps of Engineers. He has been active at the national level with ASCE's Technical Council on Computing and Information Technology (TCCIT), Committee on Faculty Development (CFD) and Excellence in Civil Engineering Education (ExCEEd) initiative. Dr. O'Neill is a licensed Professional Engineer in California, Florida, Nevada and Virginia. He is a civil engineering program evaluator for the Accreditation Board for Engineering and Technology (ABET). He is an American Society of Civil Engineering Fellow (ASCE), a member of the American Society for Engineering Education (ASEE), and Phi Kappa Phi National Honor Society.

\section{Dr. Simeon J. Komisar, Florida Gulf Coast University}

Dr. Komisar is the Program Director of Environmental Engineering at FGCU 


\title{
Using Poll App to Improve Active Learning in an Engineering Project Management Course Offered to Civil and Environmental Engineering Students
}

\begin{abstract}
Project management knowledge areas such as cost estimating, financial evaluations and project planning tend to receive less focus in engineering curricula. Students often perceive them not as "core" knowledge in their engineering majors. Increasing engineering student interest, attention, engagement and deeper learning in these knowledge areas is a challenge. In addition to making course materials relevant to these engineering disciplines, instructors have to employ various active learning initiatives to ensure effective teaching and learning are actually taking place. This paper presents a case study of using a poll app called Poll Everywhere as an active learning activity in a required senior-level "engineering project management" course for civil and environmental engineering students. As a question driven and student active tool, the poll app was used to quickly assess the students' learning in a previous lesson. The responses were optional and not graded in order to stimulate discussion among small groups of students when working on the poll questions. The classroom setting that followed the SCALE-UP (studentcentered active learning environment for undergraduate programs) model was appropriate for such collaborative learning. The student interest, understanding and knowledge of the course content were perceived to improve among students taking classes that used the polling system compared to those taking in "control" classes that did not use this cloud-based response system. Both students and faculty recognized the benefits of this implementation for identifying knowledge gaps of the course content, having extra practice with collaborative learning and making class sessions more interactive. Polling the right questions and time management were among the challenges when implementing the system.
\end{abstract}

\section{Introduction}

Active learning can improve student interest, engagement and deeper learning of the subject matters. It is any course-related activity in which all students participate rather than simply watch a lecture and/or take notes in a class session ${ }^{1}$. Participation results in student engagement, an essential component of effective teaching practices in classrooms, which in turn results in higher levels of thinking ${ }^{2}$. A review of active learning literature found support for all forms of active learning although the results varied in strength ${ }^{3}$. A meta-analysis of 225 studies in undergraduate science, technology, engineering, and mathematics (STEM) courses found that "average examination scores improved by about $6 \%$ in active learning sections, and that students in classes with traditional lecturing were 1.5 times more likely to fail than were students in classes with active learning"4.

Many student-centered approaches have been introduced to foster active learning. The approaches that can be employed to engage a larger number of students include graffiti walls, inside-outside circles, think-pair-shares, quick writes, physical movement, and student response systems $^{5}$. Among them, the use of student response systems (SRSs), also known as audience response systems, personal response systems and classroom response systems, has become more popular in higher education ${ }^{6}$. A SRS supports "student-active, question-driven, and discussioncentered pedagogy" " and allows faculty to assess the student knowledge of the specific concepts and provide immediate feedback ${ }^{8,9}$. 
Numerous studies have evaluated the effectiveness of SRSs in the learning process. SRSs promote two interactivities, namely communication among the students and between the instructor and the students, which lead to greater articulation of student thinking, effective peerto-peer discussion and collaborative learning ${ }^{10}$. Instructors benefit by receiving more honest and immediate feedback on student comprehension and high student participation ${ }^{8}$. Other studies however did not find that SRSs resulted in higher retention ${ }^{8}$. Over dependence on an SRS, student anxiety and technical sophistication were among the weaknesses if a SRS was not used appropriately ${ }^{11}$. Nevertheless, much of the previous research was based on the use of the traditional SRSs (i.e., clickers) while cloud-based response systems (hereafter referred to as poll app) have been prevalent due to a majority of students owning an Internet-connected device nowadays $^{12}$.

The goal of this paper is to assess the use of a poll app called Poll Everywhere in an engineering project management course namely "Project Planning and Regulations", which is required for civil and environmental engineering majors. Previous studies differentiated three categories of using response systems: (i) repetition - testing the students' skills in a previous lecture's theme; (ii) wake up - testing the students' skills in the present lecture's theme; and (iii) introduction preparation for a new learning session ${ }^{13}$. The current study falls in the "repetition" category. This paper contributes to active and deeper learning techniques in engineering project management courses, especially when students are engineering majors.

\section{Related Studies}

This section focuses on recent studies that were based on cloud-based response systems such as Top Hat, Kahoot! and Poll Everywhere in STEM education, especially in engineering education. With the gaining popularity of BYOD ("Bring Your Own Device") in higher education, a cloudbased response system is "an intuitive, cost-effective, user-friendly technology that can enhance students' learning and classroom experience, and instructors' effectiveness in teaching course material and assessing students' command of the same by examining the results of their polls." 14

Top Hat Monocle was used for an Introductory Electric Circuits course (105 students) where several multiple-choice questions were asked with 2-5 minutes allowed for response during each lecture $^{15}$. The study compared the student perceptions with those in a previous study using Top Hat in a different learning environment and did not address independent variables ${ }^{15}$.

No-stake quizzes with Kahoot! were used in Physics and Chemistry courses in an engineering school in Brazil for reinforcement of knowledge ${ }^{16}$. Although high proportion of students felt positive about the use of this game-based SRS, there was no "control" class for comparison in this study. As a teaching tool, Kahoot! was found to boost students engagement, interest and learning after it was repeatedly used for five months ${ }^{17}$. Most recently, a study conducted in Arkansas Tech University found that Kahoot! was able to work well for some classes, but the allowable student response time in Kahoot! did not go beyond 120 seconds $^{18}$. There is however a way to extend this time limit for answering each question in Kahoot! ${ }^{19}$.

The use of Poll Everywhere in engineering education was reported in the past six years. A pilot study that used Poll Everywhere in a large introductory computing course (over 100 students) for non-computer science majors in fall 2013 found a strong positive response from the students in 
Embry-Riddle Aeronautical University ${ }^{20}$. The authors acknowledged a limitation of a response bias that those who enjoyed using Poll Everywhere could be more likely to respond to their survey $^{20}$. There were 79 responses out of 291 students for the response rate of $27 \%$ in this pilot study. Poll Everywhere was used in three engineering courses (133 students enrolled) where some poll questions were duplicated in the exams to assess student's understanding ${ }^{21}$. The authors reported that students' conceptual understanding was improved from the poll questions to the exam questions ${ }^{21}$. The result was understandable as the authors asked the same questions in the exams. Poll Everywhere was used in Circuits course (26 students registered) in electrical engineering technology in a small-lecture classroom with the emphasis on acquisition and generalization of new knowledge ${ }^{22}$. From both faculty and student perspectives, the use of the Poll Everywhere was found effective in all phases of learning, especially during the acquisition phase 22 .

The related studies found that the use of cloud-based SRSs was positive in engineering education. However, these studies only reported the perceptions of the students who registered and participated in classes where the cloud-based SRSs were employed. To the best of the authors' knowledge, no "control" class of the same course where students did not use the cloudbased SRSs was included for comparison in these studies. This case study fills this gap by comparing the experiences and perceptions of students in classes of the same course that used and did not use the poll app.

\section{Contextual Background and Methodology}

Project Planning and Regulations has been a senior-level course required for both civil engineering and environmental majors. Being offered every fall semester, this course has been one of the prerequisites for Civil Engineering Senior Design and Environmental Engineering Senior Design. The course description is as follows:

"Introduction to techniques for planning activities, operations, finance, budget, workforce, quality, safety, and other issues related to civil and environmental engineering planning. This includes the process of locating, discovering, and studying local, state, and federal regulations/codes. The curriculum is integrated with laboratory exercises that emphasize blueprint reading, quantity takeoff and learning software packages used in cost estimating and project scheduling and controls."

Table 1 summarizes major course parameters that may affect student engagement and learning for falls 2017 and 2018. Except not using poll (2017) and using poll (2018), both semesters were similar for most of the parameters. The course content consisted of three parts: (i) project management concepts and cost estimating; (ii) project financial evaluation; and (iii) project scheduling and controls. As the summative assessments of these three parts, three exams included 10\%-15\% conceptual and 85\%-90\% quantitative material. Three quizzes were given between exams (in the middle of each part) as formative assessments. Two application projects were cost estimating/bidding (Project 1) and project scheduling (Project 2). Both projects in a semester were used the same real-world project plans and specifications. Waste activated sludge (WAS) pretreatment tanks of a wastewater treatment plant were used in fall 2017 while a storm sewer lift station was used in fall 2018. Only three MasterFormat ${ }^{\circledR}$ divisions namely concrete, earthwork, and exterior improvements were required for both projects. 
Other parameters were also similar. Two sections were available for both semesters. Both sections were taught by the same instructor who had taught this course for many years. Therefore, the "experience curve effect" of teaching was not considerable between the two consecutive years. All classrooms followed SCALE-UP (student-centered active learning environment for undergraduate programs) model though they were different in the two semesters. The classroom setting was appropriate for collaborative learning. Class sizes were also similar with a total of 58 in 2017 and 69 in 2018 (Table 1). The number of sessions and contact hours were the same for both semesters. In September of fall 2017, the campus was closed for two weeks due to the impact of a major hurricane. This resulted in a two-week extension of this semester to maintain the same number of sessions (i.e., 30).

Table 1. Comparison of course parameters between falls 2017 and 2018

\begin{tabular}{lll}
\hline Parameter & Fall 2017 & Fall 2018 \\
\hline Course content & $\begin{array}{l}\text { Three parts: project management concepts and cost } \\
\text { estimating; regulations and project financial evaluation; } \\
\text { and project scheduling and controls }\end{array}$ & Unchanged \\
Assessment & $\begin{array}{l}\text { Three quizzes }(10 \%) \text {, one legal case review (5\%), two } \\
\text { projects (20\%) and three exams (65\%)* }\end{array}$ & Unchanged \\
Instructor & Has taught this course in 15 sections since fall 2011 & Unchanged \\
Number of sections & 2 & 2 \\
Classroom & SCALE-UP & Similar** \\
Class size & 35 for morning section and 23 for afternoon section & 34 and 35 \\
Contact hours & $\begin{array}{l}\text { Two sessions per week, two contact hours for each } \\
\text { session }\end{array}$ & Unchanged \\
Number of sessions & 30 sessions. Interrupted two weeks in the earlier & 30 sessions \\
& semester due to hurricane. & Yes \\
\hline
\end{tabular}

*Homework problems with solutions were given but not graded. **Different classrooms with similar SCALE-UP model

The major change between the two semesters was the use of Poll Everywhere in fall 2018. Poll Everywhere was used for three reasons: (i) it offered more question types and answer choices; (ii) it was more flexible in displaying real-time results and customizing the number of allowable attempts and responses for each student; and (iii) it was free for both students and instructor if the number of responses in each poll was 40 or less - the class sizes in the fall 2018 offerings were 34 and 35. Except in sessions scheduled for the exams or project workdays, poll questions were used to quickly assess the students' learning in a previous lesson. In total, 26 multiplechoice, 7 open-ended and 3 clickable-image questions were polled throughout the fall 2018 semester for each section.

Two different sources of data were collected and analyzed to evaluate whether the poll implementation increased the interest, engagement and learning of the course content among engineering students. The first data source was the official student perception of instruction (SPoI) survey conducted at the end of the semester for all classes in the authors' institution. The SPoI was a survey embedded in the learning management system. In addition to the standard questions, instructors were allowed to add up to five questions specifically for each of their 
courses. Two questions were added in the SPoI in fall 2018 for this course. They were (i) "what did you like most about the use of Poll Everywhere in this class?" and (ii) "what did you like least about the use of Poll Everywhere in this class?." The second data source was a short and informal survey conducted by the authors. For both semesters, students were asked to self-assess their ability to accomplish the course objectives. In fall 2018, students were additionally asked a series of questions as to the use of poll app in this course. The questions about the use of Poll Everywhere in the informal survey were adopted from the previous studies ${ }^{10,12,23,24}$. As presented in the next section, descriptive statistics was used for data analysis.

\section{Results}

Results from SPoI and informal surveys are presented in three parts. The first part is the comparison between 2017 and 2018 with a focus of the interest and learning of the course content. The second part shows how the use of Poll Everywhere affected the engagement, interaction, and learning of the engineering students in fall 2018. The final part is the faculty reflection on the use of poll app.

\section{Comparison of Student Perceptions between Fall 2017 and Fall 2018}

Table 2 presents the results of the representative questions about students' interest and understanding of the course content in falls 2017 and 2018. The response scale of these SPoI questions was "strongly agree", "agree", "neutral", "disagree", "strongly disagree" and "not applicable." Although most students either agreed or strongly agreed the SPoI statements in both semesters, there was a significant shift from "agree" to "strongly agree" between 2017 and 2018. For example, $31 \%$ of students strongly agreed and $51 \%$ of students agreed "the instruction generated interest in the course" in 2017 while $72 \%$ strongly agreed and $26 \%$ agreed this same statement in 2018. The similar positive and significant trends were also observed in the other two statements, i.e., "the instruction helped me understand the course content" and "overall this course was effective in improving my knowledge of course content" (Table 2).

Table 2. Comparative SPoI regarding the interest and understanding of course content

\begin{tabular}{llcccc}
\hline \multirow{2}{*}{ SPoI Question } & Answer* & \multicolumn{2}{c}{ Fall 2017 } & \multicolumn{2}{c}{ Fall 2018 } \\
\cline { 3 - 5 } & & Count & $\%$ & Count & $\%$ \\
\hline The instruction generated interest in the & Strongly agree & 11 & $31 \%$ & 33 & $72 \%$ \\
course. & Agree & 18 & $51 \%$ & 12 & $26 \%$ \\
& Neutral & 5 & $14 \%$ & 0 & $0 \%$ \\
& Disagree & 1 & $3 \%$ & 1 & $2 \%$ \\
The instruction helped me understand & Strongly agree & 21 & $60 \%$ & 34 & $74 \%$ \\
the course content. & Agree & 12 & $34 \%$ & 11 & $24 \%$ \\
& Neutral & 2 & $6 \%$ & 1 & $2 \%$ \\
Overall this course was effective in & Strongly agree & 15 & $43 \%$ & 33 & $72 \%$ \\
improving my knowledge of course & Agree & 18 & $51 \%$ & 11 & $24 \%$ \\
content. & Neutral & 1 & $3 \%$ & 2 & $4 \%$ \\
& Disagree & 1 & $3 \%$ & 0 & $0 \%$ \\
\hline
\end{tabular}

*Response scale: Strongly agree, agree, neutral, disagree, strongly disagree and not applicable. Answer choices with no response for both semesters were not presented. 
Figure 1 illustrates an interesting result when comparing between the course organization and delivery. The student perception of the course organization was very similar between the two semesters (Figure 1a) but was rather different in terms of course delivery (Figure 1b). The course organization was perceived "very helpful" by $83 \%$ and $87 \%$ of students while the course delivery was perceived "very helpful" by $66 \%$ and $89 \%$ of students, in 2017 and 2018 , respectively. With the implementing the poll app, the course delivery were significantly improved whereas the course organization was still maintained.

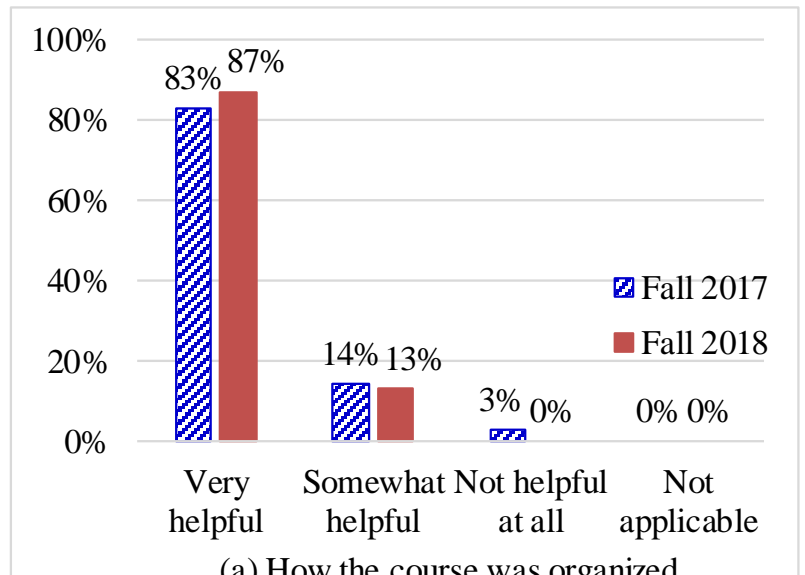

(a) How the course was organized.

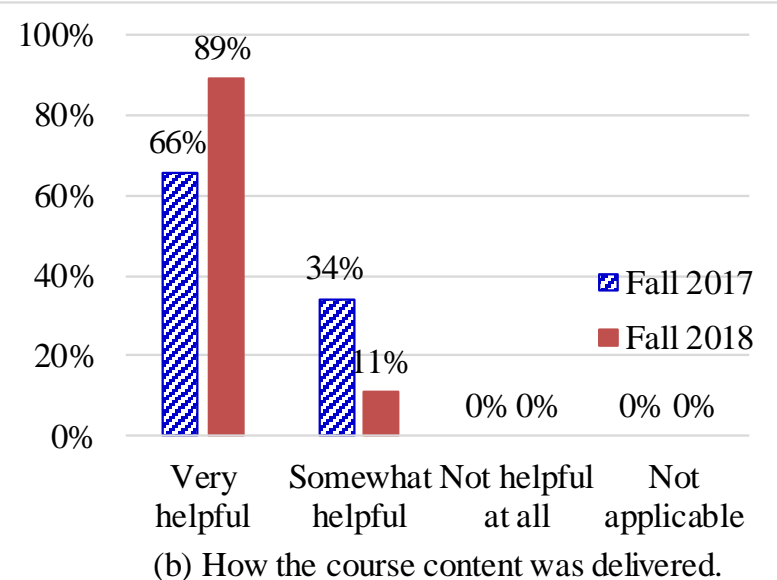

(b) How the course content was delivered.

Figure 1. Comparative SPoI regarding the organization and delivery of the course

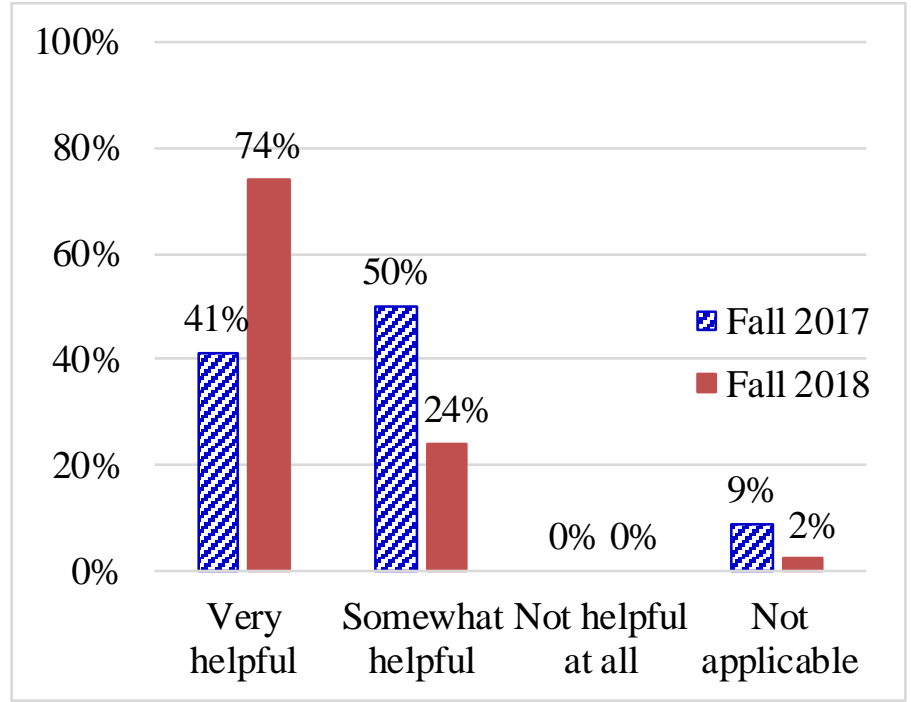

Figure 2. Comparative SPoI regarding technology utilization

The student perception of technology utilization was also improved with the use of the poll app in this class (Figure 2). This is understandable as most, if not all, students had smart phones. Using these phones for the right purposes in the classroom is challenging but feasible with response system applications. Between 2017 and 2018, the technology utilization was perceived "very helpful" increased (from $41 \%$ to $74 \%$ ) and "somewhat helpful" decreased (from 50\% to $24 \%)$. 
Table 3 presents the self-assessment of students in accomplishing each of the ten course objectives. The assessment scale consisted "unsatisfactory", "marginal", "satisfactory" and "excellent" in the informal surveys of both years. In nine course objectives, student's ability to accomplish was self-assessed higher in 2018. The achievement of the other course objective was perceived lower in 2018 but the change was very small. Nevertheless, two-sample t-tests showed that there was no significant difference between the two semesters in terms of this selfassessment at the $95 \%$ confidence level.

Table 3. Self-assessment of student's ability to accomplish course objectives

\begin{tabular}{|c|c|c|c|c|}
\hline \multicolumn{2}{|c|}{ Course objective } & \multicolumn{3}{|c|}{ Mean based on 4-point scale* } \\
\hline No. & Description & Fall 2017 & Fall 2018 & Change \\
\hline 1 & $\begin{array}{l}\text { Explain and discriminate basic concepts with regard } \\
\text { to project management }\end{array}$ & 3.55 & 3.59 & +0.04 \\
\hline 2 & $\begin{array}{l}\text { Demonstrate the ability to read and interpret } \\
\text { engineering drawings and specifications }\end{array}$ & 3.24 & 3.47 & +0.23 \\
\hline 3 & $\begin{array}{l}\text { Conduct and compile cost estimates for projects with } \\
\text { the use of different estimating methods }\end{array}$ & 3.34 & 3.50 & +0.16 \\
\hline 4 & $\begin{array}{l}\text { Explain and demonstrate regulations, standards, } \\
\text { responsibilities, and liabilities for construction } \\
\text { projects, project participants and professionals }\end{array}$ & 3.20 & 3.37 & +0.17 \\
\hline 5 & $\begin{array}{l}\text { Use communication skills to argue the basis of and } \\
\text { the need for planning, regulations, and codes. }\end{array}$ & 3.47 & 3.60 & +0.13 \\
\hline 6 & $\begin{array}{l}\text { Perform engineering economic calculations involving } \\
\text { the time value of money }\end{array}$ & 3.47 & 3.53 & +0.06 \\
\hline 7 & $\begin{array}{l}\text { Evaluate and compare project alternatives using } \\
\text { engineering economics techniques }\end{array}$ & 3.42 & 3.48 & +0.06 \\
\hline 8 & $\begin{array}{l}\text { Calculate and analyze project management } \\
\text { techniques for planning, scheduling, and controlling } \\
\text { projects }\end{array}$ & 3.39 & 3.35 & -0.04 \\
\hline 9 & $\begin{array}{l}\text { Apply basic project planning, scheduling, and control } \\
\text { techniques and tools to create project management } \\
\text { documents }\end{array}$ & 3.26 & 3.37 & +0.11 \\
\hline 10 & $\begin{array}{l}\text { Explain the value of lifelong learning in engineering } \\
\text { project management }\end{array}$ & 3.47 & 3.57 & +0.10 \\
\hline
\end{tabular}

\section{Student Perception on the Use of Poll Everywhere}

The above results inferred the positive contribution of the poll app in various aspects of teaching and learning in this course. More insight from the student perspective about the use of Poll Everywhere is necessary. The informal survey in fall 2018 included a series of questions as to the use of Poll Everywhere (Figures 3 and 4). The number of responses received from this informal survey were 68 out of 69 students enrolled in fall 2018.

Figures 3 and 4 show the student perception about the use of the poll app for class engagement and interaction and understanding the course materials, respectively. At least three quarters of students either agreed or strongly agreed and only $5 \%$ or less disagreed or strongly disagreed 
with the survey statements. Eighty seven (87\%) percent of students either strongly agreed (61\%) or agreed $(25 \%)$ that using poll improved their engagement in this class. The use of the poll app also made the class more interactive ( $78 \%$ strongly agreed) and facilitated student interaction with peers and instructor (84\% strongly agreed or agreed) (Figure 3). The poll also helped highlight gaps in student knowledge and understand course materials. Sixty nine (69\%) percent of students strongly agreed that poll questions highlighted gaps in their knowledge (Figure 4). The number of students agreed or strongly agreed a bit less in the statements that poll questions helped better prepared for the quizzes ( $76 \%$ of responses) and exams (75\% of responses).

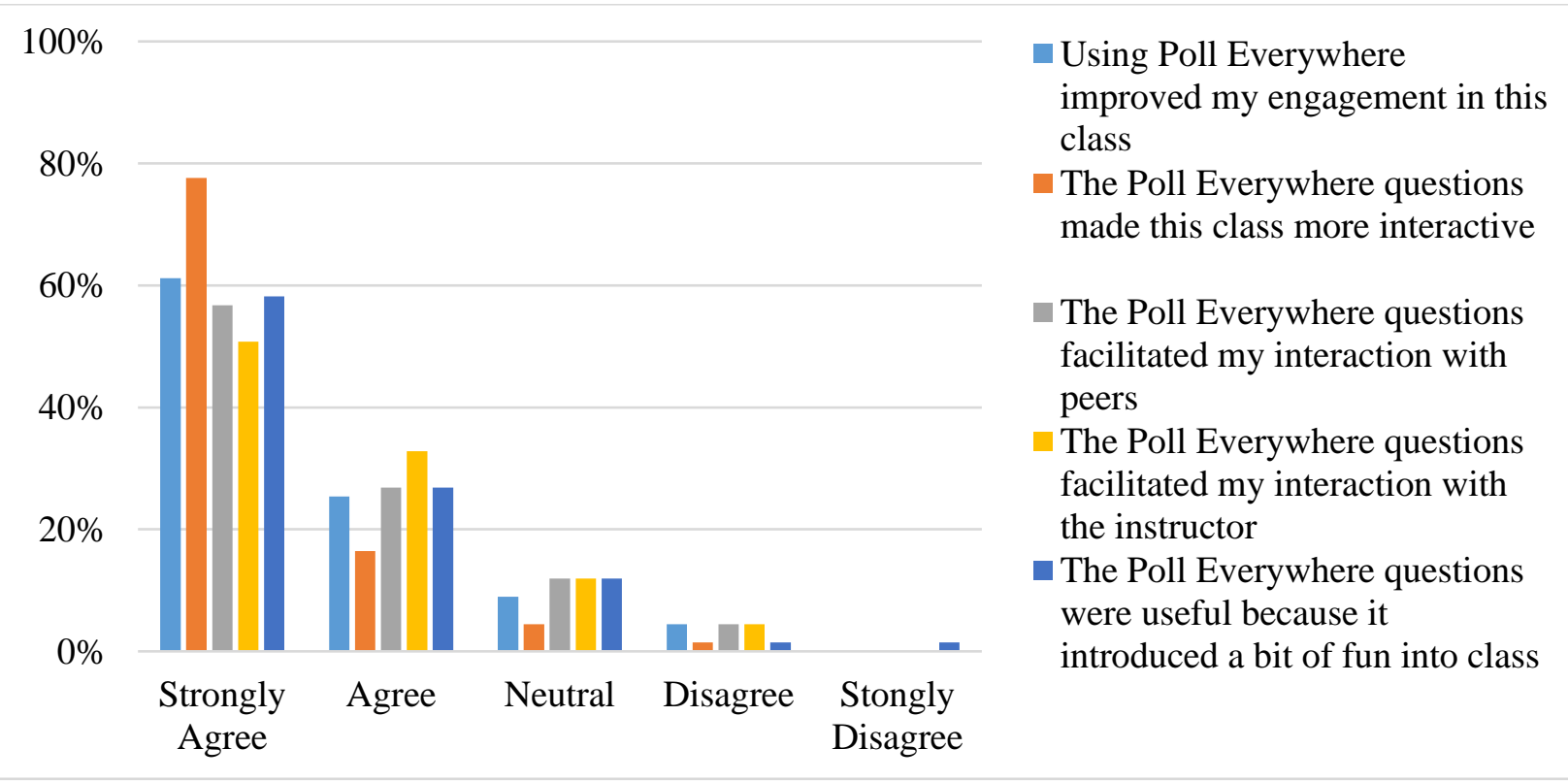

Figure 3. Student perception about the use of poll app for class engagement and interaction

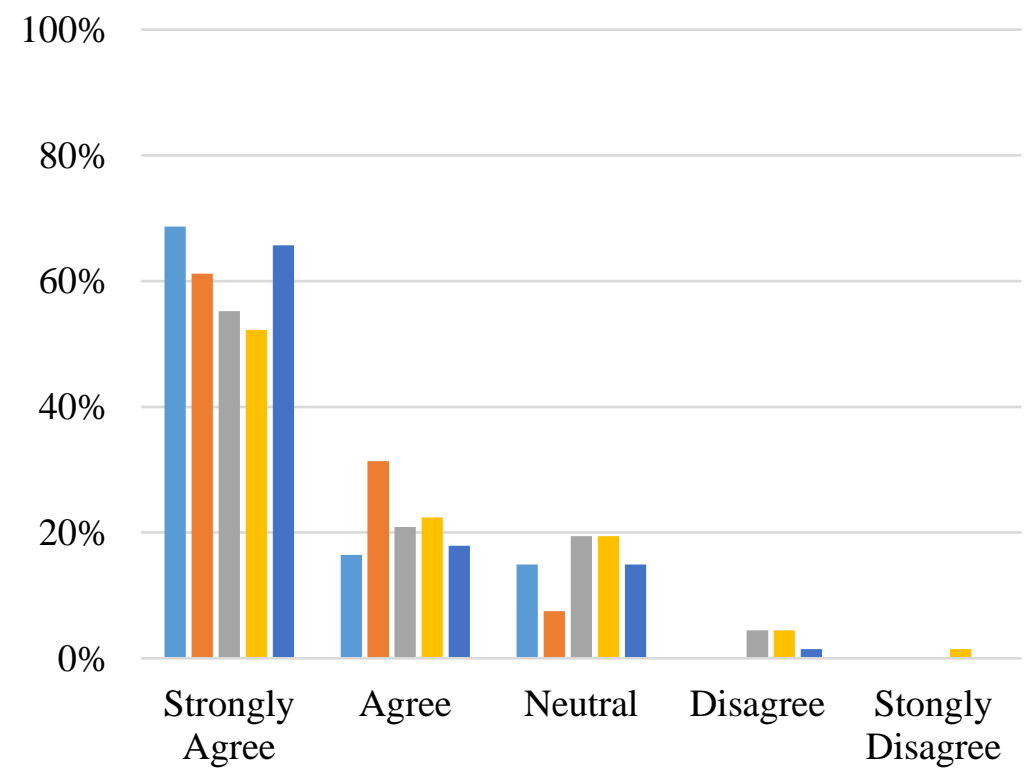

The Poll Everywhere questions highlighted gaps in my knowledge

- Using Poll Everywhere helped my understanding of course materials

The Poll Everywhere questions helped me better prepared for the quizzes

The Poll Everywhere questions helped me better prepared for the exams

- Students' responses to the Poll Everywhere questions helped the instructor understand where students had difficulty

Figure 4. Student perception about the use of poll app for understanding course materials 


\section{Faculty Reflection on the Use of Poll Everywhere}

The use of Poll Everywhere in the current course offered several benefits in many aspects of teaching and learning. It enhanced active learning and interaction with peers for problem solving. It should be noted that in both semesters the instructor provided worksheets with practice problems or case studies depending on topics to apply the course materials. The poll was an additional tool to promote active learning while refreshing information from previous lessons and identify knowledge gaps. It provided extra practice to apply the course concepts. The poll questions seemed to make class more interactive.

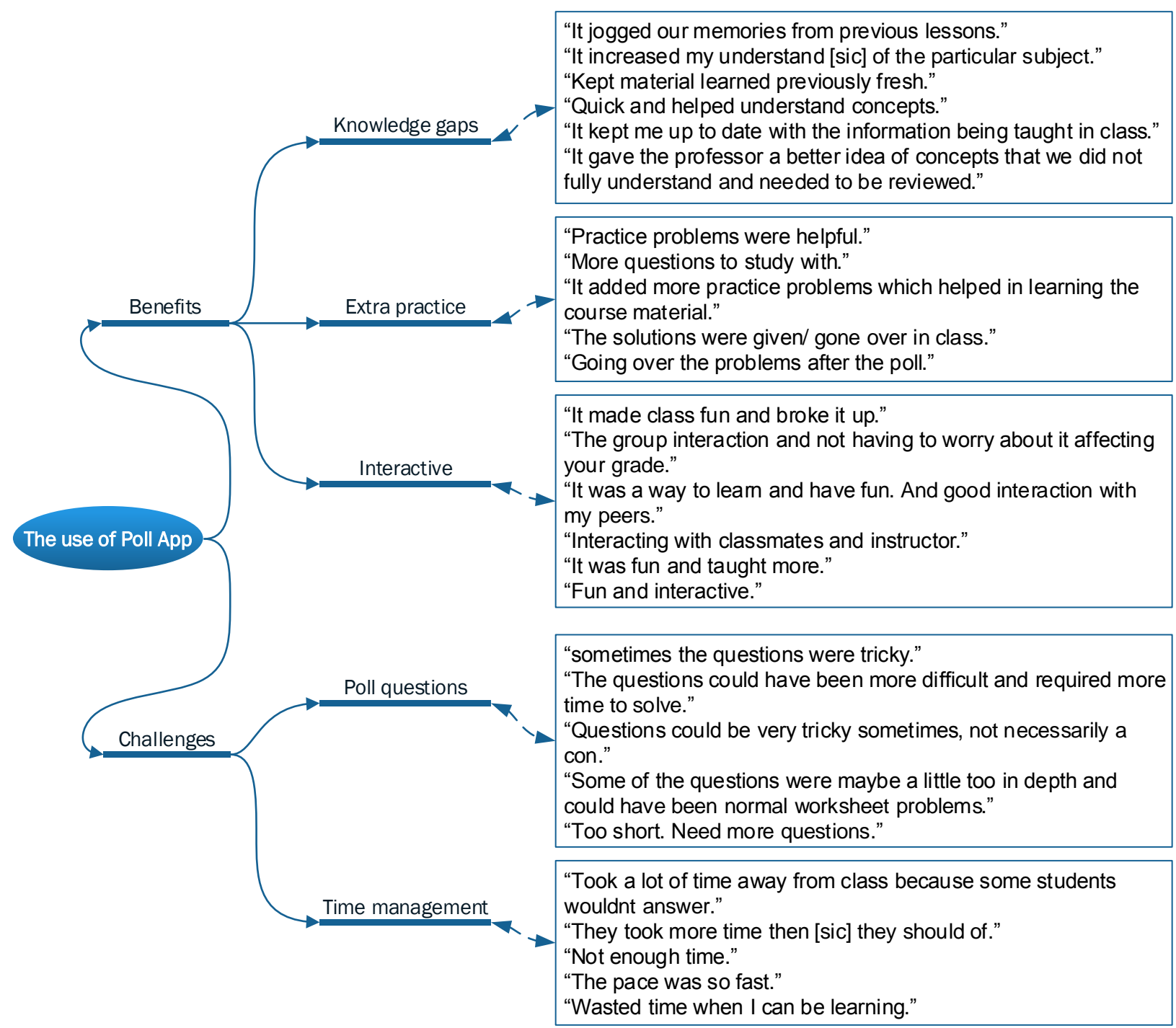

Figure 6. Benefits and challenges of using the poll app

Figure 6 summarizes benefits and challenges of using the poll app in the course from the reflection of the faculty in addition to the feedback from students. The quotes provided in Figure 6 are student responses from the two open-ended questions added to the official SPoI survey as described in the methodology. The two questions were (i) "what did you like most about the use of Poll Everywhere in this class?" and (ii) "what did you like least about the use of Poll Everywhere in this class?" There were a total of 46 responses to each of the two questions. The 
responses to the first question could be grouped into active learning benefits, including identifying knowledge gaps, providing extra practice, and being more interactive. Figure 6 includes quotes chosen from students' responses.

Among another 46 responses to the second question, 24 responses seemed to find nothing that students did not like about the use of Poll Everywhere in this class. Examples of these responses were "N/A", "None", "Nothing", or "i [sic] don't think there was anything $\mathrm{i}$ [sic] didn't like about it." Nevertheless, the use of Poll Everywhere posed some challenges for both students and instructor. Two major challenges included asking the right poll questions and time management. The quotes from students' responses were demonstrated in Figure 6. Several students stated that poll questions were sometimes tricky. Every poll question should therefore have a clear pedagogical purpose and should not just have a topic to address ${ }^{7}$. In addition, there was a small group of students who either considered poll questions too short or too long. Time management was another challenge as the pace of solving problems and responding to poll questions was different from student to student. While some students considered it fast paced, others thought that the poll took more time than it should (Figure 6). In the first part of the semester, questions were polled at the beginning of the class. There was idle time for some students when they had to wait for other students to respond, especially those who were tardy and the instructor wanted high poll participation. The instructor then changed the time to poll $20-30$ minutes later after covering new materials. The time management seemed much better because everyone was ready for poll questions. This change also helped students stay more active throughout a class session.

\section{Conclusions}

The implementation of the poll app appeared to show the increased engagement and learning when teaching an engineering project management course to civil and environmental engineering students. The student interest, understanding and knowledge of the course content were perceived to improve among students taking classes that used the polling system compared to those taking classes of the same course without using the system. Despite a positive change in the self-assessment of student's ability to accomplish course objectives, the change was not significant in sections that employed this cloud-based response system. Both students and faculty observed the benefits of this implementation in terms of identifying knowledge gaps of the course content delivered in the previous sessions, having extra practice with collaborative learning and improving the interactive class environment. Polling the right questions and time management (peer discussion, response time, and discussion after polling) were among the challenges.

There is some implication to be explored for future implementation of the poll app. Student responses to the poll questions might be formatively assessed as a participation grade. Counting student responses toward student's grade was considered a common approach to improve class participation $^{2}$. Nevertheless, some students could experience anxiety when their responses were included as part of their overall course grade ${ }^{12}$. These mixed recommendations reflected well in students' comments: (i) "The questions are designed to show where weaknesses are so they shouldn't be graded but they should be utilized."; and (ii) "I think Poll Everywhere was overall helpful and enhance interaction in class. They could potentially be used to document attendance as a grade." As such, whether or not counting the student responses toward the overall course grade really depends on what the purpose of questions to be polled is, when the questions are 
polled, and how student responses were assessed, i.e., for participation only or participation plus correctness.

The current study has limitations. More years of data, more comparisons with controls and more direct evidence are needed to have robust results. One comparison of the two semesters was not strong evidence for the effective use of cloud-based SRSs. The differences between the control and subject semesters could be contingent on the quality of the cohort from year to year. Though it occurred early in the control semester, the hurricane might negatively affect the student perception of the instruction. We will continue the experiment in the next offerings that have one control section and one subject section in a single semester.

\section{References}

${ }^{1}$ Felder, R. M., and Brent, R. "Active learning: An introduction." ASQ Higher Education Brief, vol. 2, no. 4, pp.1-5, 2009.

${ }^{2}$ Bakrania, S. "Getting students involved in a classroom with an iPhone app." The ASEE Computers in Education (CoED) Journal, vol. 4, no. 2, pp.11-20, 2013.

${ }^{3}$ Prince, M. "Does active learning work? A review of the research." Journal of Engineering Education, vol. 93, no. 3, pp.223-231, 2004.

${ }^{4}$ Freeman, S., Eddy, S. L., McDonough, M., Smith, M. K., Okoroafor, N., Jordt, H. and Wenderoth, M. P. “Active learning increases student performance in science, engineering, and mathematics." Proceedings of the National Academy of Sciences, vol. 111, no. 23, pp.8410-8415, 2014.

${ }^{5}$ O'Connor, K. "Class participation: Promoting in-class student engagement." Education, vol. 133, no. 3, pp.340-344, 2013.

${ }^{6}$ Heaslip, G., Donovan, P. and Cullen, J. G. "Student response systems and learner engagement in large classes." Active Learning in Higher Education, vol. 15, no. 1, pp.11-24, 2014.

${ }^{7}$ Beatty, I. "Transforming student learning with classroom communication systems." EDUCAUSE Center Applied Research (ECAR) Research Bulletin, no. 3, pp.1-13, 2004.

${ }^{8}$ Buhay, D., Best, L. A. and McGuire, L. "The effectiveness of library instruction: Do student response systems (clickers) enhance learning?." The Canadian Journal for the Scholarship of Teaching and Learning, vol. 1, no. 1, pp.1-9, 2010.

${ }^{9}$ Davis, B. "Use of classroom response systems in numerically intensive courses." Proceedings of the Canadian Engineering Education Association (CEEA), July 10, 2010.

${ }^{10}$ Blasco-Arcas, L., Buil, I., Hernández-Ortega, B. and Sese, F. J. "Using clickers in class. The role of interactivity, active collaborative learning and engagement in learning performance."

Computers \& Education, vol. 62, pp.102-110, 2013.

${ }^{11}$ Silliman, S. E. and McWilliams, L. "Observations on benefits/limitations of an audience response system." Proceedings of the 2004 ASEE Annual Conference and Exposition, Salt Lake City, UT, June 20-23, 2004.

${ }^{12}$ Dervan, P. "Increasing in-class student engagement using Socrative (an online Student Response System)." AISHE-J: The All Ireland Journal of Teaching and Learning in Higher Education, vol. 6, no. 3, pp.1801-1813, 2014.

${ }^{13}$ Arnesen, K., Korpas, G. S., Hennissen, J. E. and Stav, J. B. "Experiences with use of various pedagogical methods utilizing a student response system - motivation and learning outcome." Electronic Journal of e-Learning, vol. 11, no. 3, pp.169-181, 2013. 
${ }^{14}$ Shon, H. and Smith, L. "A review of Poll Everywhere audience response system." Journal of Technology in Human Services, vol. 29, no. 3, pp.236-245, 2011.

${ }^{15}$ Dunning, S. "Evaluation of an interactive classroom tool applied in an introductory electric circuits course." Proceedings of the ASEE $121^{\text {st }}$ Annual Conference and Exposition, Indianapolis, IN, June 15-18, 2014.

${ }^{16}$ Cutri, R., Marim, L.R., Cordeiro, J.R., Gil, H.A.C. and Guerald, C.C.T. "Kahoot, a new and cheap way to get classroom-response instead of using clickers." Proceedings of the ASEE $123^{\text {rd }}$ Annual Conference and Exposition, New Orleans, LA, June 26-29, 2016.

${ }^{17}$ Wang, A.I. "The wear out effect of a game-based student response system." Computers \& Education, vol. 82, pp.217-227, 2015.

${ }^{18}$ Young, M. G., Conry, J. P., Greco, E. C. "Implementation of electrostatics tutorials utilizing an electronic response system." Proceedings of the ASEE $125^{\text {th }}$ Annual Conference and Exposition, Salt Lake City, UT, June 24-27, 2018.

${ }^{19}$ Hahn, B, "Extending time limits beyond 120 secs - Support Chief weekly "hacks"." https://kahoot.com/blog/2017/02/24/extending-time-limits-beyond-120-secs/, 2017 (Accessed: January 16, 2019).

${ }^{20}$ Kappers, W. M. and Cutler, S. L. "Poll Everywhere! Even in the classroom: An investigation into the impact of using PollEverwhere in a large-lecture classroom." Computers in Education Journal, vol. 6, no. 20, p.140-145, 2015.

${ }^{21}$ Sun, L. and Tang, Y. "Enhancing conceptual understanding by using a real-time online class response system in engineering courses." Proceedings of the ASEE $125^{\text {th }}$ Annual Conference and Exposition, Seattle, WA, June 14-17, 2015.

${ }^{22}$ Popescu, O., Chezan, L. C., Jovanovic, V. M. and Ayala, O. M. "The use of Polleverywhere in engineering technology classes to stimulate student critical thinking and motivation."

Proceedings of the ASEE 125 th Annual Conference and Exposition, Seattle, WA, June 14-17, 2015.

${ }^{23}$ Auras, R. and Bix, L. "Wake up! The effectiveness of a student response system in large packaging classes." Packaging Technology and Science: An International Journal, vol. 20, no. 3, pp.183-195, 2007.

${ }^{24}$ Barnett, J. "Implementation of personal response units in very large lecture classes: Student perceptions." Australasian Journal of Educational Technology, vol. 22, no. (4), 2006. 